\title{
The Need to Develop Standard Measures of Patient Adherence for Big Data: Viewpoint
}

Przemyslaw Kardas ${ }^{1}$, Prof Dr, MD, PhD; Isabel Aguilar-Palacio ${ }^{2,3}, \mathrm{MD}, \mathrm{MPH}, \mathrm{PhD}$; Marta Almada ${ }^{4}$, PhD; Caitriona Cahir ${ }^{5}$, BA, HDip, PhD; Elisio Costa ${ }^{4}$, Prof Dr, PhD; Anna Giardini ${ }^{6}$, PsyD, MSc; Sara Malo ${ }^{2,3}$, PharmB, PhD; Mireia Massot Mesquida ${ }^{7}$, PharmB; Enrica Menditto ${ }^{8,9}$, PharmD, PhD; Luís Midão ${ }^{4}$, MSc; Carlos Luis Parra-Calderón ${ }^{10}$, MSc; Enrique Pepiol Salom ${ }^{11}$, MPharm, PGCert; Bernard Vrijens ${ }^{12,13}$, PhD

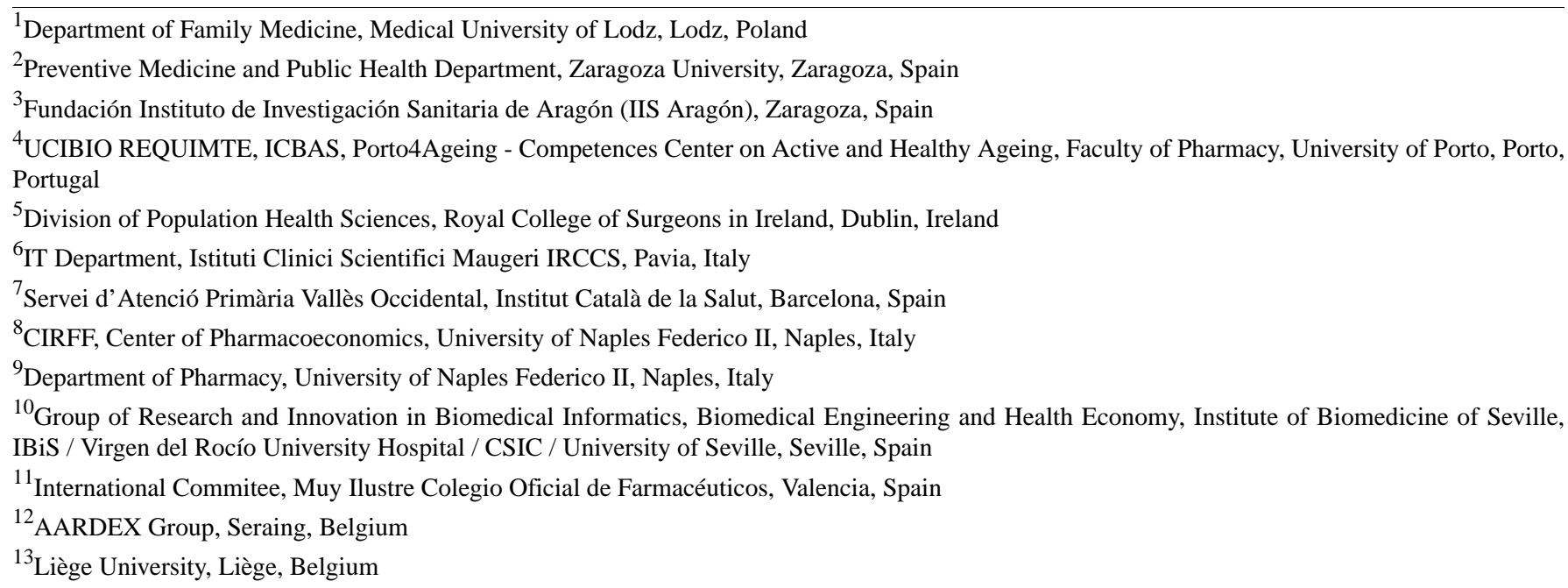

\section{Corresponding Author:}

Przemyslaw Kardas, Prof Dr, MD, PhD

Department of Family Medicine

Medical University of Lodz

60, Narutowicza St.

Lodz, 90-136

Poland

Phone: 486787210

Email: pkardas@csk.am.lodz.pl

\begin{abstract}
Despite half a century of dedicated studies, medication adherence remains far from perfect, with many patients not taking their medications as prescribed. The magnitude of this problem is rising, jeopardizing the effectiveness of evidence-based therapies. An important reason for this is the unprecedented demographic change at the beginning of the 21st century. Aging leads to multimorbidity and complex therapeutic regimens that create a fertile ground for nonadherence. As this scenario is a global problem, it needs a worldwide answer. Could this answer be provided, given the new opportunities created by the digitization of health care? Daily, health-related information is being collected in electronic health records, pharmacy dispensing databases, health insurance systems, and national health system records. These big data repositories offer a unique chance to study adherence both retrospectively and prospectively at the population level, as well as its related factors. In order to make full use of this opportunity, there is a need to develop standardized measures of adherence, which can be applied globally to big data and will inform scientific research, clinical practice, and public health. These standardized measures may also enable a better understanding of the relationship between adherence and clinical outcomes, and allow for fair benchmarking of the effectiveness and cost-effectiveness of adherence-targeting interventions. Unfortunately, despite this obvious need, such standards are still lacking. Therefore, the aim of this paper is to call for a consensus on global standards for measuring adherence with big data. More specifically, sound standards of formatting and analyzing big data are needed in order to assess, uniformly present, and compare
\end{abstract}


patterns of medication adherence across studies. Wide use of these standards may improve adherence and make health care systems more effective and sustainable.

(J Med Internet Res 2020;22(8):e18150) doi: 10.2196/18150

\section{KEYWORDS}

patient adherence; big data; metrics; consensus

\section{Introduction}

Despite half a century of dedicated studies, medication adherence remains far from perfect. In fact, nonadherence to medication (ie, the scenario in which patients are not taking their medications as prescribed) is still very prevalent. According to the World Health Organization (WHO), 50\% of patients are estimated to deviate from their chronic treatments [1]. It has been shown to lead to poor health outcomes, increased use of health services, and increased costs (both direct and indirect, eg, due to absenteeism, lost productivity, etc), jeopardizing the effectiveness of evidence-based therapies [2]. In a recent meta-analysis, medication nonadherence was found to be associated with all-cause hospitalization (adjusted odds ratio $1.17,95 \%$ CI 1.12-1.21) and mortality (good adherence was associated with a $21 \%$ reduction in long-term mortality risk in comparison with medication nonadherence; adjusted hazard ratio 0.79 , 95\% CI $0.63-0.98$ ) in older people [3]. Thus, nonadherence is an important determinant of individual health. At the population level, it also seriously affects public health and the economy. Considering all these effects, nonadherence has been recognized by the WHO as a "problem of striking magnitude" [1].

Unfortunately, the seriousness of this problem is ever increasing. An important reason for this is the unprecedented demographic change that is taking place at the beginning of the 21 st century. It affects the whole world and is particularly pronounced in Europe. According to Eurostat, currently, persons aged 65 years or older comprise $20 \%$ of the EU-28 population, and this proportion is expected to rise up to $31 \%$ by 2100 . Even more striking are the statistics for very old citizens; the proportion of persons aged 80 years or older is expected to rise within the same time period from $6 \%$ (current) of the EU-28 population to $15 \%[4]$.

Longer lifespan results in an increase in the prevalence of noncommunicable chronic conditions and multimorbidity (usually defined as the coexistence of two or more chronic conditions in an individual). This, in turn, leads to the frequent use of complex therapeutic regimens and creates a fertile ground for nonadherence [5].

In order to prevent nonadherence, one needs to know the major drivers of this phenomenon. The WHO developed a model of the determinants affecting adherence and grouped them into five main sets of factors as follows: health system-related factors, therapy-related factors, condition-related factors, patient-related factors, and socioeconomic factors [1]. Based on this model of adherence, multiple nonadherence-targeting interventions have been designed and tested, but unfortunately, only few have been successful. As stated in a recent Cochrane systematic review, "current methods of improving medication adherence for chronic health problems are mostly complex and not very effective, so the full benefits of treatment cannot be realized" [6].

Indeed, medication taking is a complex behavior, and diverse determinants play different roles at the individual level. As a consequence, it seems to be unrealistic to expect that one uniform intervention will solve the problem of nonadherence in each and every case. On the other hand, there is a rising body of evidence that nonadherence could be effectively managed through the use of various innovative digital solutions [7]. Successful examples include web-based education and monitoring programs [8], clinical decision support systems using data from electronic health records (EHRs) to produce alerts [9], mobile technologies (mobile health [mHealth]), dedicated apps providing various combinations of patient monitoring, education, and facilitation of adherence [10,11], etc. Owing to digitization, for the first time in history, nonadherence may also become precisely measurable on a mass scale owing to the availability of large health care databases. This is particularly important for older populations, which is a group usually understudied in clinical trials for various reasons (eg, multimorbidity and related polymedication).

However, these promising opportunities are not fully utilized yet owing to a lack of basic widely accepted standards for measuring and managing adherence in big data. The discussion that started in 2019 at the forums of professional bodies active in the area of patient adherence research (ie, Action Group A1 "Adherence to prescription and medical plans" of the European Innovative Partnership on Active and Healthy Ageing and International Society for Medication Adherence ESPACOMP), to which the authors of this publication belong, led to the conclusion that this scenario needs to be changed. This idea corresponds very well with recent recommendations of the Heads of Medicines Agencies-European Medicines Agency joint Big Data Task Force, which called for the development of skills and the creation of capabilities to analyze big data [12]. Therefore, the aim of this publication is to establish a call for a consensus on global standards for measuring adherence with big data. More specifically, sound standards of formatting and analyzing big data are needed in order to assess, uniformly present, and compare patterns of medication adherence across studies, and thus, help scientific research, clinical practice, and public health.

\section{Opportunities Created for Adherence Owing to Digitization of the Health Care Sector}

Digitization is a new opportunity that has, in recent times, become more frequently adopted in the health care sector. 
Interestingly, to date, digital solutions have been widely used outside health care, but they have only recently been employed in the field of medicine and offer great promise toward improved and more efficient care. In order to speed up this process, in 2018, the European Commission developed a plan for the digital transformation of health and care in the Digital Single Market. The plan is based on three pillars as follows: (1) securing data access and sharing; (2) connecting and sharing health data for research, faster diagnosis, and improved individualized health care services and health outcomes; and (3) strengthening citizen empowerment and individual care through digital services [13]. This plan is a part of the overarching European Strategy for Data [14]. Digitization of the health care sector creates an opportunity for using big data analytics tools and methods to assess nonadherence, improve clinical practice or health care services, and promote the use of tailored interventions. Routinely collected information on prescribing and dispensing, which are available in EHRs, pharmacy dispensing databases, health insurance claims systems, and national health systems records, enables a more thorough exploration of the relationship between adherence and health outcomes. The rising use of mHealth by patients for self-monitoring and disease management is also another potential data source for analysis. Thus, big data may represent a powerful and relatively low-cost resource for investigating important public health concerns in real-life scenarios, including the prevalence of nonadherence, its drivers, and the consequences of nonadherence. Big data can also be used to provide information for designing new interventions and targeting both prevention and management of nonadherence. Moreover, big data allow research on an incomparable scale, covering large populations (eg, primary nonadherence, a measure of unfilled prescriptions, was recently assessed in a cohort of 1.6 million Catalonian primary care patients [15] and in a national population based study in Poland [16]). Unlike medical trials, big data also provide an opportunity to assess adherence longitudinally (eg, an Estonian study analyzed a national database over a period of 15 years [17]). All this is possible without typical limitations in terms of cost, intrusiveness, and bias, which are characteristic of studies employing other sorts of data for adherence measurement and monitoring. However, at present, uniform and accepted standards of adherence measurement for big data are still lacking. Moreover, currently, big data collection is not uniformly formatted or structured for adherence measurement, which means that nontrivial operations are needed to allow for this kind of analysis. Therefore, to build a solid evidence base for adherence management across clinical settings, it is necessary to standardize adherence estimation and facilitate the appropriate use of these standards [18].

Adherence research is not the only area of research facing problems with standardization when it comes to digital health. For example, there are no global standards for EHRs [19]. Various historical, cultural, economic, and political reasons could be cited as causative factors, and despite activities of several interoperability initiatives, both public and private, this is still the case [20]. Several standardization development organizations have developed very mature and widely implemented standards, such as the Clinical Document Architecture [21] and Fast Healthcare Interoperability Resources
[22] by HL7, and CEN-ISO 13606 [23], but they are limited in their interoperability. Interestingly, ISO 10781:2015 provides a reference list of functions that may be present in an EHR system, and of these, the following function tackles adherence assessment: Care Patient Support CPS 3.1 Function on "Support for Standard Assessments" [24].

A systemic review of the challenges for the use of big data in health care identified issues in data structure, security, data standardization, storage and transfer, and managerial skills, such as data governance, to be the most often provided in the current literature [25]. Practical challenges included data preprocessing and curation, model training, refinement of systems, ethical and legal issues, data privacy and security, end users understanding acceptance, etc [26,27].

Certainly, to overcome all these challenges is not easy. However, it is quite easy to illustrate why this scenario urgently needs to be changed.

\section{Need for Standard Big Data-Related Adherence Metrics for Research}

The introduction of the Ascertaining Barriers for Compliance taxonomy (ABC taxonomy) and new adherence terminology (named after the dedicated European research project "Ascertaining Barriers for Adherence") made the first big step forward in terms of standardization by defining three essential components of adherence. These components are as follows: (1) initiation (taking the first dose of the prescribed medication); (2) implementation (taking medication as prescribed); and (3) discontinuation (stopping treatment) [28]. Following this, the recently introduced EMERGE (ESPACOMP Medication Adherence Reporting Guideline developed under the umbrella of the International Society for Medication Adherence, COMpliance, and Persistence [ESPACOMP]) provides guidance, along with a checklist for reporting results of studies on medication adherence [29]. Other interesting activities in this area include the work initiated with the support of the Government of Spain and the European project StandICT.eu to generate an extension of the SNOMED CT terminology for the domain of adherence [30] and the proposal to include terms of adherence in the amendment to ISO 13940 (system of concepts to support continuity of care) currently in progress in ISO TC 215 [31].

However, there are still many challenges with the use of big data for adherence assessment. Without standard metrics, the same data may lead to diverse results, as clearly depicted in the study by Malo et al, which found different mean adherence values and proportions of adherent patients when using medication possession ratio versus proportion of days covered [32].

To date, numerous studies on adherence have been undertaken, using diverse approaches to data analysis, which have led to mixed results. Most often, pharmacy records are used to measure adherence in terms of implementation and discontinuation [33]. EHR data have also been used for effective prediction of medication adherence trajectories [34], which has evoked certain discussions [35]. Menditto et al managed to integrate and 
analyze six databases from three countries, which allowed for a fair comparison of medication adherence across the various countries [36]. Another study managed to assess and compare adherence to chronic medication across three European cohorts of older people by developing a common protocol and using structured documents for sharing and applying methodologies [37].

Some attempts to introduce standards to adherence assessment in big data have been made by the International Society for Pharmacoeconomics and Outcomes Research (ISPOR). The ISPOR Medication Adherence and Persistence Special Interest Group produced recommendations for assessment of initial medication adherence [38] and proposed a checklist for medication adherence studies using retrospective databases [39]. Arnet et al [40] and Raebel et al [41] proposed standard definitions and their operationalization to quantify adherence to medication from electronic databases. Lehnman et al [42] and Williams et al [43] provided some basic guidance regarding the use of pharmacy refill data to assess adherence. At the same time, a systematic review of publications on adherence in older Americans identified as many as 20 differently named measures of adherence derived from pharmacy claims data [44]. Even more interestingly, some adherence measures derived from big data are already in use for incentivizing health care providers to consider long-term health outcomes. In the United States, the Centers for Medicare \& Medicaid Services adopted several quality measures using the threshold of the proportion of days covered of $\geq 0.8$ for the drugs under measurement, for a period of 12 consecutive months [45]. In fact, there is evidence that this improves adherence [46].

Moreover, another important question that needs to be addressed in future standardized measures of adherence in big data is "what is the subject of adherence assessment: a drug, a condition, or a patient?" In other words, how to measure adherence to multiple medications prescribed for the same condition and/or to various conditions in patients with multimorbidity [47]. Indicators designed and widely used to evaluate single-medication adherence are not necessarily valid for the assessment of adherence to polypharmacy regimens [48]. For example, a study assessing adherence in individuals belonging to the Epichron cohort returned highly diverse results for various drug classes as follows: $72.4 \%$ for antidiabetics versus only $44.3 \%$ for lipid-lowering drugs [49]. A recent systematic review found serious inconsistency in the measures used to estimate adherence and persistence to multiple cardiometabolic medications [50], while another review concluded that "there appears to be no standardized method to measure multiple medication adherence" [51]. For sure, further research is needed in this respect and is particularly important given the aging population.

In summary, the major disadvantage of the current lack of widely accepted standards for adherence assessment is the difficulty in comparing and interpreting scientific studies' results. Uniform adherence measurement and a common ontology urgently need to be developed in order to support research and enable real-life implementation of study findings [40,52,53]. This is also necessary for cross-study comparisons and fair benchmarking of adherence-targeting interventions.

\section{Need for Standard Big Data-Related Adherence Metrics for Clinical Practice, Public Health, and Health Policy}

Big data and the development of a standardized measure of adherence may enable more reliable and valid investigations into the association between nonadherence and health outcomes. To date, there is no consensual standard for what constitutes adequate adherence. In practice, $80 \%$ is often used as a cutoff to classify "good adherence," but scientific evidence for this threshold is unclear. In fact, a systematic review investigated medication adherence thresholds in relation to clinical outcomes and found the included studies to be highly heterogeneous, and it could not confirm or reject the validity of the historical $80 \%$ cutoff threshold for adherence [54]. Moreover, many treatments are also preventative, and it may take a very long time to determine any therapeutic benefit at all from such treatments.

Various interventions have been designed to prevent and manage nonadherence in real-life settings. Unfortunately, despite objective need, these interventions are generally underused. Lack of standardized comparable measures of adherence is one of the major barriers to the objective selection of the most effective and cost-effective interventions [2] and the scaling-up of the best practice. Only with reliable and valid measures can nonadherence be tracked along a timeline, allowing the assessment of the long-term effects of particular interventions and the benchmarking of their effectiveness. Standard measures and guidelines to assess adherence could also facilitate the introduction as well as the assessment of the effectiveness of incentives to promote adherence at the patient, provider, and payer levels and the ability to target individual risk factors at the various health care provider levels [55].

Standardized adherence measures employed in big data sets may also provide insights into the reasons why patients do not adhere to their prescribed medication regimens. This is of utmost importance as a review of systematic reviews identified 771 individual factor items as possible determinants of nonadherence, concluding that "lack of standardized adherence definitions and use of poor measurement methods resulted in many inconsistencies in the findings and many of the identified factors had an inconsistent effect on adherence" [56].

Thus, big data sets are useful to assess adherence in different profiles of drug users, analyze the factors related to adherence, explore causes of discontinuation, and compare results across different populations. With this information, drug users at the highest risk of nonadherence can be identified, and tailored interventions can be designed and implemented. It is of paramount importance to consider that most of the current interventions to address adherence are using or are based on information technology (IT) solutions. These, however, are not currently based on standardized measures of adherence [55]. Another potential technology approach for prediction and assessment of adherence is artificial intelligence (AI). With AI, big data may be analyzed both retrospectively and in real time, allowing for more personalized health care. However, a major hindrance to the adoption of AI is, yet again, the lack of sound 
operational measures of adherence to properly train the algorithms.

Along with individual health, public health is sure to benefit from the introduction of standardized measures of adherence. Such measures will enable comparison of adherence rates within and across different countries, populations, and disease groups, allowing for fair benchmarking of interventions, better planning, and practical implementation. In fact, more often, medication adherence is accepted as a measure of the quality of care provided by physicians, as well as the quality and effectiveness of the entire health care system [55,57]. Moreover, in this area, a lack of standardized measures causes the problem of nonadherence to be often overlooked in national agendas. Currently, only few countries systematically monitor adherence. Therefore, the recent Organization for Economic Co-operation and Development (OECD) report calls for standardization in order to allow for international benchmarking [55].

The recent outbreak of the COVID-19 pandemic has shown the extraordinary role that infoepidemiology (ie, information epidemiology) can play in the management of major public health problems [58]. Let this lesson be an inspiration for the wider adoption of digitization in health care in general and the faster utilization of the potential of big data for the management of adherence in particular.

\section{Conclusions}

Ongoing digitization of the health care sector and availability of big data repositories create an unprecedented opportunity to study patient adherence on a mass scale both retrospectively and in real time. Obvious benefits that could be derived for science, as well as individual and public health, are hindered by the current lack of standards for adherence-related data analysis. What sort of standards need to be agreed upon to change this scenario? First, there needs to be a standard format for the data collected in big data databases, such as EHRs and prescribing and dispensing registers, to allow for smooth and effective assessment of adherence parameters. Second, sound metrics need to be developed to process the raw data. Third, the standards of presentation of adherence measures being assessed within big data need to be agreed upon.

Bearing in mind the troublesome history of health care sector digitization, this plan may appear to be ambitious. However, the authors of this paper are motivated to face the challenge and develop these highly needed global standards, discuss them with the scientific world, and finally, agree on a common consensus. Therefore, interested individuals are invited to join our efforts within the new initiative that we want to call DIGI.PASs (Patient Adherence Standard measures to be used with big data collections available in DIGItal repositories).

\section{Conflicts of Interest}

PK received speaker honoraria from Aflofarm, Fresenius, Polpharma, and Sandoz and received grant funding from European Union's Horizon 2020 for GATEKEEPER project (grant agreement number 857223) and The European Commission ERASMUS+ Project Skills4Adherence (grant agreement number: 2017-1-PL01-KA202-038672), outside of this work. BV is the CEO and shareholder of AARDEX Group.

\section{References}

1. Sabaté E. Adherence to Long-term Therapies: Evidence for Action. Geneva: World Health Organization; 2003.

2. Cutler RL, Fernandez-Llimos F, Frommer M, Benrimoj C, Garcia-Cardenas V. Economic impact of medication non-adherence by disease groups: a systematic review. BMJ Open 2018 Jan 21;8(1):e016982 [FREE Full text] [doi: 10.1136/bmjopen-2017-016982] [Medline: 29358417]

3. Walsh CA, Cahir C, Tecklenborg S, Byrne C, Culbertson MA, Bennett KE. The association between medication non-adherence and adverse health outcomes in ageing populations: A systematic review and meta-analysis. Br J Clin Pharmacol 2019 Nov;85(11):2464-2478. [doi: 10.1111/bcp.14075] [Medline: $\underline{31486099}$ ]

4. European Comission. The EU's population projected up to 2100. Eurostat. URL: https://ec.europa.eu/eurostat/web/ products-eurostat-news/-/DDN-20190710-1 [accessed 2020-04-13]

5. Wong MC, Liu J, Zhou S, Li S, Su X, Wang HH, et al. The association between multimorbidity and poor adherence with cardiovascular medications. Int J Cardiol 2014 Dec 15;177(2):477-482. [doi: 10.1016/j.ijcard.2014.09.103] [Medline: 25443249]

6. Nieuwlaat R, Wilczynski N, Navarro T, Hobson N, Jeffery R, Keepanasseril A, et al. Interventions for enhancing medication adherence. Cochrane Database Syst Rev 2014 Nov 20(11):CD000011 [FREE Full text] [doi: 10.1002/14651858.CD000011.pub4] [Medline: 25412402]

7. Car J, Tan WS, Huang Z, Sloot P, Franklin BD. eHealth in the future of medications management: personalisation, monitoring and adherence. BMC Med 2017 Apr 05;15(1):73 [FREE Full text] [doi: 10.1186/s12916-017-0838-0] [Medline: 28376771]

8. Linn AJ, Vervloet M, van Dijk L, Smit EG, Van Weert JC. Effects of eHealth interventions on medication adherence: a systematic review of the literature. J Med Internet Res 2011 Dec 05;13(4):e103 [FREE Full text] [doi: 10.2196/jmir.1738] [Medline: 22138112]

9. Bailey SC, Wallia A, Wright S, Wismer GA, Infanzon AC, Curtis LM, et al. Electronic Health Record-Based Strategy to Promote Medication Adherence Among Patients With Diabetes: Longitudinal Observational Study. J Med Internet Res 2019 Oct 21;21(10):e13499 [FREE Full text] [doi: 10.2196/13499] [Medline: $\underline{\text { 31638592] }}$ 
10. Hamine S, Gerth-Guyette E, Faulx D, Green BB, Ginsburg AS. Impact of mHealth chronic disease management on treatment adherence and patient outcomes: a systematic review. J Med Internet Res 2015 Feb 24;17(2):e52 [FRE Full text] [doi: 10.2196/jmir.3951] [Medline: 25803266]

11. Pérez-Jover V, Sala-González M, Guilabert M, Mira JJ. Mobile Apps for Increasing Treatment Adherence: Systematic Review. J Med Internet Res 2019 Jun 18;21(6):e12505 [FREE Full text] [doi: 10.2196/12505] [Medline: 31215517]

12. Priority Recommendations of the HMA-EMA joint Big Data Task Force. European Medicines Agency. URL: https://www. ema.europa.eu/en/documents/other/priority-recommendations-hma-ema-joint-big-data-task-force_en.pdf [accessed 2020-04-13]

13. eHealth: Digital health and care. European Commission. URL: https://ec.europa.eu/health/ehealth/overview en [accessed 2020-04-13]

14. European data strategy: Making the EU a role model for a society empowered by data. European Commission. URL: $\underline{\text { https:/ }}$ lec.europa.eu/info/strategy/priorities-2019-2024/europe-fit-digital-age/european-data-strategy [accessed 2020-04-13]

15. Aznar-Lou I, Fernández A, Gil-Girbau M, Fajó-Pascual M, Moreno-Peral P, Peñarrubia-María MT, et al. Initial medication non-adherence: prevalence and predictive factors in a cohort of 1.6 million primary care patients. Br J Clin Pharmacol 2017 Jun;83(6):1328-1340 [FREE Full text] [doi: 10.1111/bcp.13215] [Medline: 28229476]

16. Kardas P, Cieszyński J, Czech M, Banaś I, Lewek P. Primary nonadherence to medication and its drivers in Poland: findings from the electronic prescription pilot analysis. Pol Arch Intern Med 2020 Jan 31;130(1):8-16 [FREE Full text] [doi: 10.20452/pamw.14994] [Medline: 31559971]

17. Laius O, Pisarev H, Maasalu K, Kõks S, Märtson A. Adherence to osteoporosis medicines in Estonia-a comprehensive 15-year retrospective prescriptions database study. Arch Osteoporos 2017 Dec;12(1):59. [doi: 10.1007/s11657-017-0354-z] [Medline: 28643266]

18. Dima A, Allemann S, Dediu D. AdhereR: An Open Science Approach to Estimating Adherence to Medications Using Electronic Healthcare Databases. Stud Health Technol Inform 2019 Aug 21;264:1451-1452. [doi: 10.3233/SHTI190479] [Medline: $\underline{31438176}$ ]

19. OECD. Health in the 21st Century: Putting Data to Work for Stronger Health System. In: OECD Health Policy Studies. Paris: OECD Publishing; 2019.

20. Auffray C, Balling R, Barroso I, Bencze L, Benson M, Bergeron J, et al. Making sense of big data in health research: Towards an EU action plan. Genome Med 2016 Jun 23;8(1):71 [FREE Full text] [doi: 10.1186/s13073-016-0323-y] [Medline: 27338147]

21. Master Grid of Standards. Health Level Seven International. URL: https://www.hl7.org/implement/standards/product brief. cfm?product_id=7V [accessed 2020-04-13]

22. Welcome to FHIR. HL7. URL: https://www.hl7.org/fhir/ [accessed 2020-04-13]

23. ISO 13606-1:2019 Health informatics — Electronic health record communication — Part 1: Reference model. ISO. URL: https://www.iso.org/standard/67868.html [accessed 2020-04-13]

24. ISO/HL7 10781:2015 Health Informatics — HL7 Electronic Health Records-System Functional Model, Release 2 (EHR FM). ISO. URL: https://www.iso.org/standard/57757.html [accessed 2020-04-13]

25. Kruse CS, Goswamy R, Raval Y, Marawi S. Challenges and Opportunities of Big Data in Health Care: A Systematic Review. JMIR Med Inform 2016 Nov 21;4(4):e38 [FREE Full text] [doi: 10.2196/medinform.5359] [Medline: 27872036]

26. Ngiam KY, Khor IW. Big data and machine learning algorithms for health-care delivery. The Lancet Oncology 2019 May;20(5):e262-e273. [doi: 10.1016/S1470-2045(19)30149-4]

27. Shortreed SM, Cook AJ, Coley RY, Bobb JF, Nelson JC. Challenges and Opportunities for Using Big Health Care Data to Advance Medical Science and Public Health. Am J Epidemiol 2019 May 01;188(5):851-861. [doi: 10.1093/aje/kwy292] [Medline: 30877288]

28. Vrijens B, De Geest S, Hughes DA, Przemyslaw K, Demonceau J, Ruppar T, Project Team ABC. A new taxonomy for describing and defining adherence to medications. Br J Clin Pharmacol 2012 May;73(5):691-705 [FREE Full text] [doi: 10.1111/j.1365-2125.2012.04167.x] [Medline: 22486599]

29. De Geest S, Zullig LL, Dunbar-Jacob J, Helmy R, Hughes DA, Wilson IB, et al. ESPACOMP Medication Adherence Reporting Guideline (EMERGE). Ann Intern Med 2018 Jul 03;169(1):30-35. [doi: 10.7326/M18-0543] [Medline: 29946690]

30. Final Impact Report: Europe's Contributions To ICT Standardisation Globally - Impacts From StandlCT.Eu Funding. StandlCT.eu. URL: https://www.standict.eu/publications/

final-impact-report-europe \%E2\%80\%99s-contributions-ict-standardisation-globally-impacts [accessed 2020-04-13]

31. Adherence and Integrated Care. BioPortal. URL: https://bioportal.bioontology.org/ontologies/ADHER_INTCARE_EN [accessed 2020-04-13]

32. Malo S, Aguilar-Palacio I, Feja C, Lallana MJ, Rabanaque MJ, Armesto J, et al. Different approaches to the assessment of adherence and persistence with cardiovascular-disease preventive medications. Curr Med Res Opin 2017 Jul;33(7):1329-1336. [doi: 10.1080/03007995.2017.1321534] [Medline: 28422521]

33. Lima-Dellamora ED, Osorio-de-Castro CG, Madruga LG, Azeredo TB. Use of pharmacy records to measure treatment adherence: a critical review of the literature. Cad Saude Publica 2017 Apr 20;33(3):e00136216 [FREE Full text] [doi: 10.1590/0102-311X00136216] [Medline: 28444026] 
34. Franklin JM, Gopalakrishnan C, Krumme AA, Singh K, Rogers JR, Kimura J, et al. The relative benefits of claims and electronic health record data for predicting medication adherence trajectory. Am Heart J 2018 Mar;197:153-162. [doi: 10.1016/j.ahj.2017.09.019] [Medline: 29447776]

35. Zullig LL, Curtis LH. A population health perspective on a claims and electronic health record-based tool to screen for suboptimal medication adherence. Am Heart J 2018 Mar;197:150-152. [doi: 10.1016/j.ahj.2017.10.012] [Medline: 29447775]

36. Menditto E, Bolufer De Gea A, Cahir C, Marengoni A, Riegler S, Fico G, et al. Scaling up health knowledge at European level requires sharing integrated data: an approach for collection of database specification. Clinicoecon Outcomes Res 2016;8:253-265 [FREE Full text] [doi: 10.2147/CEOR.S97548] [Medline: 27358570]

37. Menditto E, Cahir C, Aza-Pascual-Salcedo M, Bruzzese D, Poblador-Plou B, Malo S, et al. Adherence to chronic medication in older populations: application of a common protocol among three European cohorts. Patient Prefer Adherence 2018;12:1975-1987 [FREE Full text] [doi: 10.2147/PPA.S164819] [Medline: 30323567]

38. Hutchins DS, Zeber JE, Roberts CS, Williams AF, Manias E, Peterson AM, IPSOR Medication AdherencePersistence Special Interest Group. Initial Medication Adherence-Review and Recommendations for Good Practices in Outcomes Research: An ISPOR Medication Adherence and Persistence Special Interest Group Report. Value Health 2015 Jul;18(5):690-699 [FREE Full text] [doi: 10.1016/j.jval.2015.02.015] [Medline: 26297098]

39. Peterson AM, Nau DP, Cramer JA, Benner J, Gwadry-Sridhar F, Nichol M. A checklist for medication compliance and persistence studies using retrospective databases. Value Health 2007;10(1):3-12 [FREE Full text] [doi:

10.1111/j.1524-4733.2006.00139.x] [Medline: 17261111]

40. Arnet I, Kooij MJ, Messerli M, Hersberger KE, Heerdink ER, Bouvy M. Proposal of Standardization to Assess Adherence With Medication Records: Methodology Matters. Ann Pharmacother 2016 May;50(5):360-368. [doi: 10.1177/1060028016634106] [Medline: 26917817]

41. Raebel MA, Schmittdiel J, Karter AJ, Konieczny JL, Steiner JF. Standardizing terminology and definitions of medication adherence and persistence in research employing electronic databases. Med Care 2013 Aug;51(8 Suppl 3):S11-S21 [FREE Full text] [doi: 10.1097/MLR.0b013e31829b1d2a] [Medline: 23774515]

42. Lehmann A, Aslani P, Ahmed R, Celio J, Gauchet A, Bedouch P, et al. Assessing medication adherence: options to consider. Int J Clin Pharm 2014 Feb;36(1):55-69. [doi: 10.1007/s11096-013-9865-x] [Medline: 24166659]

43. Williams AB, Amico KR, Bova C, Womack JA. A proposal for quality standards for measuring medication adherence in research. AIDS Behav 2013 Jan;17(1):284-297 [FREE Full text] [doi: 10.1007/s10461-012-0172-7] [Medline: 22407465]

44. Sattler EL, Lee JS, Perri M. Medication (re)fill adherence measures derived from pharmacy claims data in older Americans: a review of the literature. Drugs Aging 2013 Jun;30(6):383-399. [doi: 10.1007/s40266-013-0074-z] [Medline: 23553512]

45. Quality Measures. U.S. Centers for Medicare \& Medicaid Services. URL: https://www.cms.gov/Medicare/ Quality-Initiatives-Patient-Assessment-Instruments/QualityMeasures/index?redirect=/qualitymeasures/ [accessed 2020-04-13]

46. Parekh N, Munshi KD, Hernandez I, Gellad WF, Henderson R, Shrank WH. Impact of Star Rating Medication Adherence Measures on Adherence for Targeted and Nontargeted Medications. Value Health 2019 Nov;22(11):1266-1274. [doi: 10.1016/j.jval.2019.06.009] [Medline: $\underline{31708063]}$

47. Kim S, Bennett K, Wallace E, Fahey T, Cahir C. Measuring medication adherence in older community-dwelling patients with multimorbidity. Eur J Clin Pharmacol 2018 Mar;74(3):357-364. [doi: 10.1007/s00228-017-2388-y] [Medline: 29199370]

48. Arnet I, Greenland M, Knuiman MW, Rankin JM, Hung J, Nedkoff L, et al. Operationalization and validation of a novel method to calculate adherence to polypharmacy with refill data from the Australian pharmaceutical benefits scheme (PBS) database. Clin Epidemiol 2018;10:1181-1194 [FREE Full text] [doi: 10.2147/CLEP.S153496] [Medline: 30233252]

49. Moreno Juste A, Gimeno Miguel A, Poblador Plou B, González Rubio F, Aza Pascual-Salcedo MM, Menditto E, et al. Adherence to treatment of hypertension, hypercholesterolaemia and diabetes in an elderly population of a Spanish cohort. Med Clin (Barc) 2019 Jul 05;153(1):1-5. [doi: 10.1016/j.medcli.2018.10.023] [Medline: 30503066]

50. Alfian SD, Pradipta IS, Hak E, Denig P. A systematic review finds inconsistency in the measures used to estimate adherence and persistence to multiple cardiometabolic medications. J Clin Epidemiol 2019 Apr;108:44-53 [FREE Full text] [doi: 10.1016/j.jclinepi.2018.12.003] [Medline: 30537541]

51. Pednekar PP, Ágh T, Malmenäs M, Raval AD, Bennett BM, Borah BJ, et al. Methods for Measuring Multiple Medication Adherence: A Systematic Review-Report of the ISPOR Medication Adherence and Persistence Special Interest Group. Value Health 2019 Feb;22(2):139-156 [FREE Full text] [doi: 10.1016/j.jval.2018.08.006] [Medline: 30711058]

52. Dima AL, Dediu D. Computation of adherence to medication and visualization of medication histories in R with AdhereR: Towards transparent and reproducible use of electronic healthcare data. PLoS One 2017;12(4):e0174426 [FREE Full text] [doi: 10.1371/journal.pone.0174426] [Medline: 28445530]

53. Román-Villarán E, Pérez-Leon FP, Escobar-Rodriguez GA, Parra-Calderón CL. EIP on AHA Ontology for adherence: Knowledge representation advanced tools. Transl Med UniSa 2019;19:49-53 [FREE Full text] [Medline: 31360667]

54. Baumgartner PC, Haynes RB, Hersberger KE, Arnet I. A Systematic Review of Medication Adherence Thresholds Dependent of Clinical Outcomes. Front Pharmacol 2018;9:1290 [FREE Full text] [doi: 10.3389/fphar.2018.01290] [Medline: 30524276]

55. Khan R, Socha-Dietrich K. Investing in medication adherence improves health outcomes and health system efficiency: Adherence to medicines for diabetes, hypertension, and hyperlipidaemia. In: OECD Health Working Papers No. 105. Paris: OECD Publishing; 2018:1-40. 
56. Kardas P, Lewek P, Matyjaszczyk M. Determinants of patient adherence: a review of systematic reviews. Front Pharmacol 2013;4:91 [FREE Full text] [doi: 10.3389/fphar.2013.00091] [Medline: 23898295]

57. Seabury SA, Dougherty JS, Sullivan J. Medication adherence as a measure of the quality of care provided by physicians. Am J Manag Care 2019 Feb;25(2):78-83 [FREE Full text] [Medline: 30763038]

58. Mavragani A. Tracking COVID-19 in Europe: Infodemiology Approach. JMIR Public Health Surveill 2020 Apr 20;6(2):e18941 [FREE Full text] [doi: 10.2196/18941] [Medline: $\underline{32250957]}$

\title{
Abbreviations
}

AI: artificial intelligence

EHR: electronic health record

EMERGE: ESPACOMP Medication Adherence Reporting Guideline

ESPACOMP: European Society for Patient Adherence, COMpliance, and Persistence

ISO: International Organization for Standardization

ISPOR: International Society for Pharmacoeconomics and Outcomes Research

IT: information technology

WHO: World Health Organization

\author{
Edited by G Eysenbach; submitted 08.02.20; peer-reviewed by TT Meum, PM Matricardi; comments to author 18.03.20; revised \\ version received 26.04.20; accepted 22.06.20; published 27.08.20 \\ Please cite as: \\ Kardas P, Aguilar-Palacio I, Almada M, Cahir C, Costa E, Giardini A, Malo S, Massot Mesquida M, Menditto E, Midão L, \\ Parra-Calderón CL, Pepiol Salom E, Vrijens B \\ The Need to Develop Standard Measures of Patient Adherence for Big Data: Viewpoint \\ J Med Internet Res 2020;22(8):e18150 \\ URL: http://www.jmir.org/2020/8/e18150/ \\ doi: $10.2196 / 18150$ \\ PMID: 32663138
}

CPrzemyslaw Kardas, Isabel Aguilar-Palacio, Marta Almada, Caitriona Cahir, Elisio Costa, Anna Giardini, Sara Malo, Mireia Massot Mesquida, Enrica Menditto, Luís Midão, Carlos Luis Parra-Calderón, Enrique Pepiol Salom, Bernard Vrijens. Originally published in the Journal of Medical Internet Research (http://www.jmir.org), 27.08.2020. This is an open-access article distributed under the terms of the Creative Commons Attribution License (https://creativecommons.org/licenses/by/4.0/), which permits unrestricted use, distribution, and reproduction in any medium, provided the original work, first published in the Journal of Medical Internet Research, is properly cited. The complete bibliographic information, a link to the original publication on http://www.jmir.org/, as well as this copyright and license information must be included. 